\title{
SUPER EDGE-CONNECTIVITY AND ZEROTH-ORDER RANDIĆ INDEX ${ }^{1}$
}

\author{
ZHIHONG $\mathrm{HE}^{2}$ \\ School of Mathematics and Information Science \\ Yantai University, Yantai, 264005, China \\ e-mail: zhihhe@126.com \\ AND \\ MEI LU \\ Department of Mathematical Science \\ Tsinghua University, Beijing 100084, China \\ e-mail: mlu@math.tsinghua.edu.cn
}

\begin{abstract}
Define the zeroth-order Randić index as $R^{0}(G)=\sum_{x \in V(G)} \frac{1}{\sqrt{d_{G}(x)}}$, where $d_{G}(x)$ denotes the degree of the vertex $x$. In this paper, we present two sufficient conditions for graphs and triangle-free graphs, respectively, to be super edge-connected in terms of the zeroth-order Randić index.

Keywords: zeroth-order Randić index, super edge-connected, degree, trianglefree graph, minimum degree.
\end{abstract}

2010 Mathematics Subject Classification: 05C20.

\section{REFERENCES}

[1] D. Bauer, F.T. Boesch, C. Suffel and R. Tindell, Connectivity extremal problems and the design of reliable probabilistic networks, in: The Theory and Application of Graphs, G. Chartrand, Y. Alavi, D. Goldsmith, L. Lesniak Foster and D. Lick $(\operatorname{Ed}(\mathrm{s})$ ), (Wiley, New York, 1981) 45-54.

[2] F. Boesch, On unreliability polynomials and graph connectivity in reliable network synthesis, J. Graph Theory 10 (1986) 339-352. doi:10.1002/jgt.3190100311

\footnotetext{
${ }^{1}$ Natural Science Funds of China (No.11501490, 61373019, 13071107) and by the Natural Science Foundation of Shandong Province (No. ZR2015AM006).

${ }^{2}$ Corresponding author.
} 
[3] J.A. Bondy and U.S.R. Murty, Graph Theory with Application (Elsevier, New York, 1976).

[4] G. Chartrand, A graph-theoretic approach to a communications problem, SIAM J. Appl. Math. 14 (1966) 778-781. doi: $10.1137 / 0114065$

[5] Z. Chen, G. Su and L. Volkmann, Sufficient conditions on the zeroth-order general Randić index for maximally edge-connected graphs, Discrete Appl. Math. 218 (2017) $64-70$.

doi:10.1016/j.dam.2016.11.002

[6] P. Dankelmann, A. Hellwig and L. Volkmann, Inverse degree and edge-connectivity, Discrete Math. 309 (2009) 2943-2947.

doi:10.1016/j.disc.2008.06.041

[7] P. Dankelmann and L. Volkmann, New sufficient conditions for equality of minimum degree and edge-connectivity, Ars Combin. 40 (1995) 270-278.

[8] P. Dankelmann and L. Volkmann, Degree sequence condition for maximally edgeconnected graphs depending on the clique number, Discrete Math. 211 (2000) $217-223$.

doi:10.1016/S0012-365X(99)00279-4

[9] P. Dankelmann and L. Volkmann, Degree sequence condition for maximally edgeconnected graphs and digraphs, J. Graph Theory 26 (1997) 27-34. doi:10.1002/(SICI)1097-0118(199709)26:1〈27::AID-JGT4〉3.0.CO;2-J

[10] M.A. Fiol, On super-edge-connected digraphs and bipartite digraphs, J. Graph Theory 16 (1992) 545-555. doi:10.1002/jgt.3190160603

[11] A.K. Kelmans, Asymptotic formulas for the probability of $k$-connectedness of random graphs, Theory Probab. Appl. 17 (1972) 243-254. doi:10.1137/1117029

[12] L.B. Kier and L.H. Hall, The nature of structure-activity relationships and their relation to molecular connectivity, European J. Med. Chem. 12 (1977) 307-312.

[13] L.B. Klein and L.H. Hall, Molecular Connectivity in Structure Activity Analysis (Research Studies Press, Wiley, Chichester, UK, 1986).

[14] L. Lesniak, Results on the edge-connectivity of graphs, Discrete Math. 8 (1974) 351-354. doi:10.1016/0012-365X(74)90154-X

[15] A. Lin, R. Luo and X. Zha, On sharp bounds of the zeroth-order general Randić index of certain unicyclic graphs, Appl. Math. Lett. 22 (2009) 585-589. doi:10.1016/j.aml.2008.06.035

[16] L. Plesník and S. Znám, On equality of edge-connectivity and minimum degree of a graph, Arch. Math. (Brno) 25 (1989) 19-25. 
[17] T. Soneoka, Super-edge-connectivity of dense digraphs and graphs, Discrete Appl. Math. 37/38 (1992) 511-523.

doi:10.1016/0166-218X(92)90155-4

[18] G. Su, L. Xiong, X. Su and G. Li, Maximally edge-connected graphs and zeroth-order general Randić index for $\alpha \leq-1$, J. Comb. Optim. 31 (2016) 182-195. doi:10.1007/s10878-014-9728-y

[19] Y. Tian, L. Guo, J. Meng and C. Qin, Inverse degree and super edge-connectivity, Int. J. Comput. Math. 89 (2012) 752-759. doi:10.1080/00207160.2012.663491

[20] P. Turán, Eine Extremalaufgabe aus der Graphentheorie, Mat. Fiz. Lapook 48 (1941) 436-452.

Received 12 April 2017 Revised 19 April 2018 Accepted 8 June 2018 